\title{
Selective hippocampal lesions and behavior
}

\author{
LEONARD E. JARRARD \\ Washington and Lee University, Lexington, Virginia 24450
}

\begin{abstract}
The hypothesis that neuroanatomically discrete areas within hippocampus are differentially involved in behavior was studied in rats, using selective lesions involving either the fimbria, CA1 cells, and/or posterior alveus. Damage to the fimbria with the resulting interruption of rostral connections with subcortical structures is similar to extensive hippocampal lesions in causing increases in behavioral arousal and increased susceptibility to interference. Damage to CA1 cells and/or posterior alveal lesions that interrupt caudal hippocampal projections toward cortical areas have relatively little effect on behavior but do result in impaired acquisition of complex spatial tasks. Since damage to fimbria and alveus interrupts fibers of passage, thus complicating interpretation of the results, the use of chemical lesioning techniques with more discrete damage to hippocampal subdivisions should prove of value in future research.
\end{abstract}

The research I will describe falls into two categories: (1) studies designed to determine the possibility that the different subdivisions within the hippocampal formation are differentially involved in behavior and (2) research that indicates there may be increased susceptibility to interference when the hippocampal connections with subcortical structures are interrupted.

General agreement concerning any one theory of hippocampal function has been lacking. This is not surprising, since a variety of effects on behavior are found when the hippocampus is experimentally manipulated (see reviews by Douglas, 1967; Jarrard, 1973; Kimble, 1968; Warrington \& Weiskrantz, 1973). Much of the research has been done with the assumption that the hippocampal formation functions as a unit, but recent neuroanatomical and neurophysiological data indicate important differences within the various hippocampal subdivisions. The assumption in the behavioral research I will describe is that by using selective lesions involving neuroanatomically discrete areas of the hippocampus, evidence for the involvement of the various areas in specific behavioral processes can be obtained. If it can be shown that different subdivisions are involved in, for example, motivation (arousal), response control, or endocrine functioning, then this would have important implications for theories concerning the involvement of the hippocampus in learning and memory.

\section{Neuroanatomical Considerations}

In this paper, the term "hippocampus" will be used to include both the various cell fields of the hippocampus proper (or Ammon's horn) and the dentate gyrus (see Gottlieb \& Cowan, 1973). The general term

The research reported in this paper was supported by grants from the National Science Foundation (BNS 75-18160, BNS 7809802). Requests for reprints should be sent to Leonard E. Jarrard, Department of Psychology, Washington and Lee University, Lexington, Virginia 24450. "hippocampal formation" will include the cell fields, dentate gyrus, and related subicular cortical regions. Since the time of the pioneering work of Lorente de No $(1933,1934)$, the hippocampus has been divided into several cytoarchitectonic cell fields (CA1 through CA4) ${ }^{1}$ More recent electrophysiological and anatomical research has indicated that the hippocampal formation contains a neuronal circuit consisting of the following cellular areas and pathways: entorhinal cortex $\rightarrow$ perforant path $\rightarrow$ dentate gyrus $\rightarrow$ mossy fibers $\rightarrow$ CA3 cell field $\rightarrow$ Schaffer collaterals $\rightarrow$ CA1 cell field $\rightarrow$ alveus $\rightarrow$ subiculum $\rightarrow$ entorhinal cortex (Andersen, Bland, \& Dudar, 1973; HjorthSimonsen, 1973; Swanson, Wyss, \& Cowan, 1978). The CA3 cells bifurcate forming (1) Schaffer collaterals and (2) other fibers that project primarily through fimbria to the septum. An important feature of hippocampal circuitry is that the structure may be regarded as being divided into series of lamellae or narrow strips that are organized at right angles to the septotemporal axis. Each lamella contains perforant path-dentate gyrus-CA3-CA1 connections that project primarily to the other components on that plane (Andersen, Bliss, \& Skrede, 1971; Rawlins \& Green, 1977; Ruth \& Routtenberg, 1978).

The efferent and afferent connections of the hippocampus are rather complex and were not well understood until the last several years. In an important paper in 1966, Raisman, Cowan, and Powell reported that the hippocampal cell fields CA1 and CA3 have differential connections to subcortical structures through the dorsal fornix and fimbria, respectively. Subsequent research by Andersen et al. (1973) demonstrated that axons from the CA1 cell field project in a caudal direction through alveus toward the subiculum and entorhinal cortex. More recent neuroanatomical research employing autoradiographic and horseradish peroxidase techniques has indicated that the hippocampal projections are more complex than 
reported in the earlier studies (Meibach \& Siegel, 1977; Rosen \& Van Hoesen, 1977; Swanson, 1979; Swanson \& Cowan, 1977). It is interesting that the septal region is the only subcortical area to receive inputs from the hippocampus proper and that the number of fibers involved is apparently relatively small (Swanson \& Cowan, 1977). The septal region receives inputs from both CA3 cells (bilateral) and CA1 cells (ipsilateral) as well as inputs from the adjacent subicular areas. Although the number of axons that project to septum from CA3 and CA1 cell fields is not known, it has been suggested that they are approximately equal (Swanson, Note 1). Swanson and Cowan (1977) estimate that there are approximately 150,000 cells in the CA3 field, 300,000 CA1 cells, and from 50,000 to 100,000 axons in the fimbria-fornix (with some of these being from septum and others from subiculum). Thus, these investigators suggest that, on numerical grounds, the rostral projections from Ammon's horn are a relatively minor part of the hippocampal outflow.

Caudal projections from hippocampus toward subiculum and entorhinal cortex were described early (Andersen et al., 1973; Hjorth-Simonsen, 1971, 1973) but were recently found by Swanson and Cowan (1977) to be more extensive than previously reported. Specifically, all parts of fields CA1 and CA3 project to the subiculum, and more limited parts of these fields send fibers to the pre- and parasubiculum and to the entorhinal, perirhinal, retrosplenial, and cingulate areas (Swanson, 1979). The extensive nature of these cortical connections as compared with the septal inputs from hippocampus led Swanson and Cowan to comment that "By any measure the caudally directed projection from Ammon's horn must be regarded as one of the major features of this system" (p. 80).

A surprising finding of recent research is that hippocampal formation fibers found in the descending columns of the fornix do not have their cells of origins in hippocampus proper but, rather, in the subiculum (Meibach \& Siegel, 1977; Swanson \& Cowan, 1977). Furthermore, there are major differences in the efferent connections of the dorsal and ventral parts of the subiculum. The dorsal two-thirds of the subicular complex projects through the dorsal fornix to terminate in the mammillary complex of the hypothalamus and the anterior thalamic nuclei (Meibach \& Siegel, 1977). The ventral subiculum sends fibers through the lateral tip of fimbria to the rostral hypothalamus (via medial corticohypothalamic tract), the ventromedial hypothalamus, and to several basal forebrain structures (bed nucleus of stria terminalis, nucleus accumbens, anterior olfactory nucleus). The medial corticohypothalamic tract has points of termination in anterior and ventral hypothalamic areas that are closely linked to endocrine function (Meibach \& Siegel, 1977). This dorsal-ventral difference in subcortical projections from subiculum may prove to be of functional importance.
The hippocampus is known to receive major afferents from the septum and entorhinal cortex as well as other inputs from the brainstem. Cholinergic fibers from the medial septal nucleus are extensive, with the dentate gyrus and CA3 cells receiving the greatest input and field CA1 the least (Mellgren \& Srebro, 1973; Mosko, Lynch, \& Cotman, 1973; Swanson \& Cowan, 1977). The entorhinal cortex sends most, if not all, of its efferents to the hippocampus via the perforant path, especially to the dentate gyrus and CA3-CA4 cells (Hjorth-Simonsen, 1971; Swanson \& Cowan, 1977). However, the pyramidal cells in the CA1 field also receive limited inputs from entorhinal cortex (Steward, 1976). Brainstem inputs to hippocampus are now well established, with both noradrenergic (Koda \& Bloom, 1977; Moore, 1975; Swanson \& Hartman, 1975) and serotonergic (Moore \& Halaris, 1976; Segal, 1975) terminals having been identified.

In summary, a review of the neuroanatomy indicates there are several areas that appear to be central to the underlying circuitry of the hippocampal formation. One of these is the CA3 cell field. In addition to the Schaffer collateral projections, axons from CA3 cells provide a major extrahippocampal outflow, primarily through fimbria to the septum. By sectioning the axons in fimbria, most of the subcortical connections of the hippocampus are interrupted. A second major feature is the relatively large caudal projections from CA1 cells (and, to a lesser extent, CA3 cells) through alveus toward the subicular and entorhinal cortical areas. Damage to the alveus interrupts most of these connections. The third major feature is the subicular complex with its very different dorsal and ventral subfields that provide the major source of fibers in postcommissural fornix.

\section{Selective Hippocampal Lesions}

On the basis of the Raisman and Andersen studies, we devised early a surgical procedure using aspiration that, it was felt, would permit lesioning or deefferenting the two main cell-field subdivisions (CA1 and CA3). The different selective lesions used in our behavioral studies with rats are shown in Figure 1. In this figure, drawings of selected coronal sections showing the lesions in a representative subject from each operated group are presented.

Animals in the complete hippocampal group $(\mathrm{CH})$ received extensive damage to all cell fields including dentate gyrus, alveus, and fimbria. The amount of damage to hippocampus averages $80 \%$ to $85 \%$ and includes the fimbria, thus deefferenting the rostral projections from the part of ventral hippocampus that is usually spared by the lesion. Behavioral results obtained from animals with extensive damage to hippocampus have proved especially valuable, since they provide a baseline with which to compare more selective hippocampal damage.

Subjects in the fimbrial group (F) had bilateral 

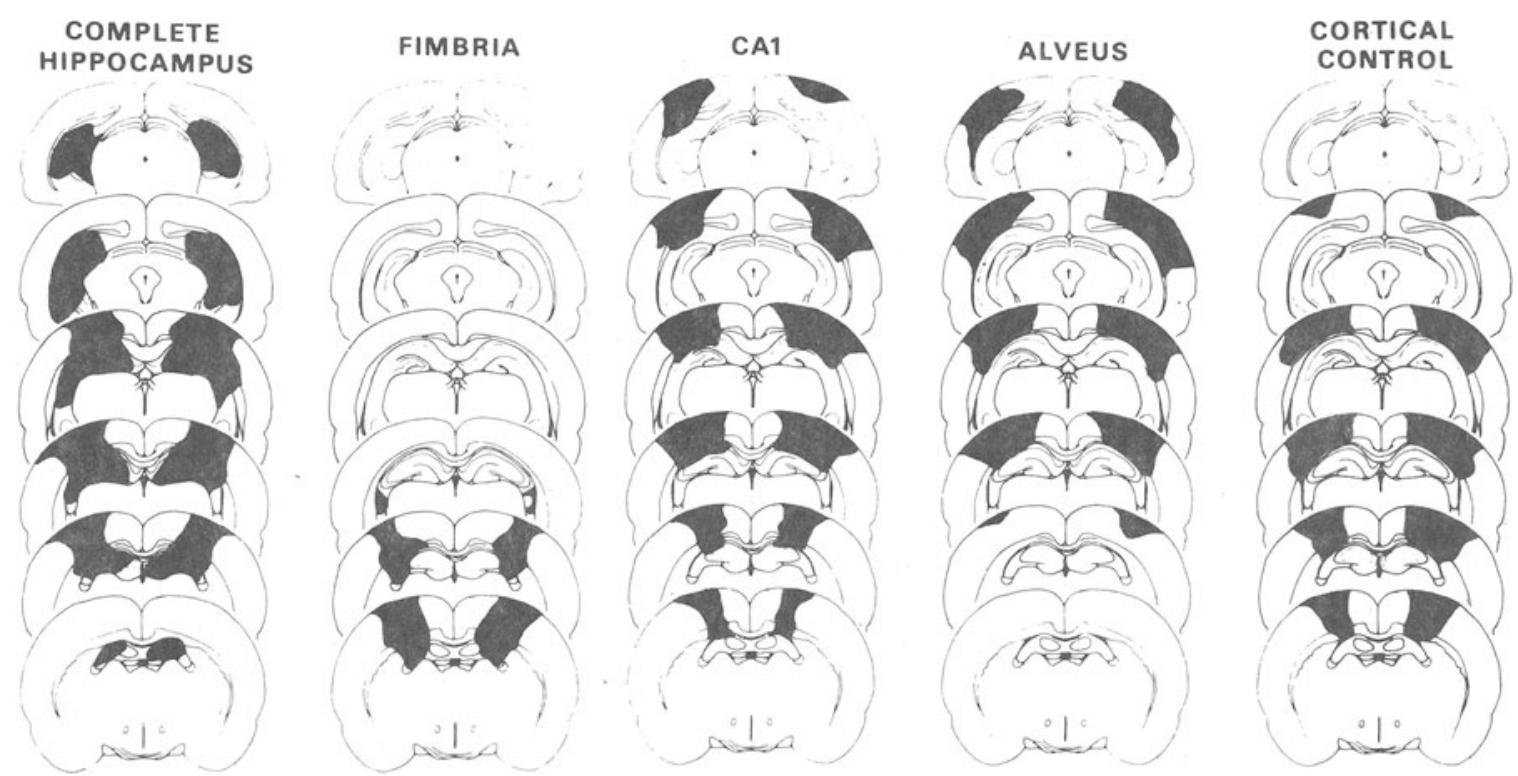

Figure 1. Tracings of coronal sections showing the lesion (in black) in a representative animal from each group.

damage that included most of the fibers in the pathway. Since the available neuroanatomy indicated that the fimbria contains most of the CA3 extrahippocampal efferent and afferent connections, it was felt that relatively effective isolation of the rostral projections of CA3 cells could be obtained by sectioning the fimbria at the level of the anterior pole of hippocampus. It is now known that the fimbria lesion also interrupts many of the rostral CA1 projections and the subicular axons, especially those in ventral subiculum, as well as septohippocampal fibers whose cells of origin are in medial septum.

The CA1 lesion consists of aspirating the neocortex overlying anterodorsal and middle hippocampus and then removing the exposed alveus and pyramidal cells in the CA1 cell field. In the alveal group (A), a more posterior and ventral approach through neocortex is used, and hippocampal damage is limited to fibers in the alveus. With our approach, $70 \%$ to $80 \%$ of the fibers in posterior alveus are damaged, thus interrupting most of the caudal projections from hippocampus.

Animals in the operated cortical control group had neocortical ablations similar to those in the $\mathrm{CH}, \mathrm{F}$, $\mathrm{CA1}$, and A groups.

A major problem in using a lesion approach to study the hippocampal formation is that fibers of passage are invariably interrupted. In the surgical preparations described above, the CA1 and alveal lesions would especially interrupt the rostral projections from dorsal subiculum, while the fimbria lesion would damage the ventral subicular fibers that traverse through the lateral tip of fimbria.

\section{Lesion Effects on Activity, Learning (Spatial \\ Reversal and Avoidance), and \\ Operant Performance}

The effects on behavior resulting from the above selective damage to hippocampal cell fields and/or projections have been studied in several experiments (Gray, Jarrard, Rawlins, \& Feldon, 1977; Jarrard, 1976, 1978a, 1978b; Jarrard \& Becker, 1977). Space does not permit a detailed consideration of this research, but the results are summarized in Table 1 . Most of the tasks had been shown in previous research to be sensitive to extensive hippocampal damage, and it was felt that with more limited lesions one could clarify the nature of the behavioral involvement of the different hippocampal regions.

In looking over the results in this table, it is surprising how similar the effects on behavior are when only the fimbria is damaged as compared with extensive damage to the hippocampus-this is the case for day-night activity, deprivation effects on activity, shuttle-box avoidance, spontaneous alternation, and operant performance (the radial maze results are discussed below). Generally, these behaviors are not affected when the CA1 cell field is damaged and/or the caudal fibers in alveus are interrupted. The exception appears to be activity in the novel open field and spatial reversal learning.

Perhaps I could comment in more detail on the activity studies. It has often been reported that damage to hippocampus results in rats' being more active in novel situations (e.g., the open field), and there is reason to believe that hippocampal damage results in changes in motivation that can perhaps best be 
Table 1

Behavioral Effects of Selective Hippocampal Lesions

\begin{tabular}{|c|c|c|c|c|c|c|}
\hline \multirow[b]{2}{*}{$\begin{array}{l}\text { Behavior } \\
\text { Tested }\end{array}$} & \multicolumn{5}{|c|}{ Summary of Results } & \multirow[b]{2}{*}{ Reference } \\
\hline & $\begin{array}{c}\text { Complete } \\
\text { Hippocampus }\end{array}$ & Fimbria & $\begin{array}{c}\text { CA1 Cell } \\
\text { Field }\end{array}$ & Alveus & $\begin{array}{l}\text { Cortical } \\
\text { Control } \\
\end{array}$ & \\
\hline \multicolumn{7}{|c|}{ Activity } \\
\hline Home Cage, Day & $\uparrow$ & $\uparrow$ & $=$ & $=$ & $=$ & Jarrard, 1976 \\
\hline Home Cage, Night & $\uparrow$ & $\uparrow$ & $\uparrow$ & $\uparrow$ & $=$ & Jarrard, 1976 \\
\hline Home Cage, Deprivation & $\uparrow$ & $\uparrow$ & $=$ & $=$ & $=$ & Jarrard, 1976 \\
\hline Open Field & $\uparrow$ & $\uparrow$ & $\uparrow$ & $\uparrow$ & $=$ & Jarrard, 1976 \\
\hline \multicolumn{7}{|c|}{ Y-Maze, Spatial } \\
\hline Acquisition & $=$ & $=$ & $=$ & $=$ & $=$ & Jarrard, 1976 \\
\hline Reversal & $\downarrow$ & $=$ & $\downarrow$ & $\downarrow$ & $=$ & Jarrard, 1976 \\
\hline \multicolumn{7}{|c|}{ Avoidance } \\
\hline Passive & $\downarrow$ & $=$ & $=$ & $=$ & $=$ & Jarrard, 1976 \\
\hline Shuttlebox & $\uparrow$ & $\uparrow$ & $=$ & $=$ & $=$ & Jarrard, 1976 \\
\hline \multicolumn{7}{|c|}{ Spontaneous Alternation } \\
\hline Spontaneous Alternation & $\downarrow$ & $\downarrow$ & $=$ & $=$ & $=$ & Unpublished \\
\hline \multicolumn{7}{|c|}{ Operant } \\
\hline FI $30 \mathrm{sec}$ & $\uparrow$ & $\uparrow$ & $=$ & $=$ & $=$ & Unpublished \\
\hline DRL $20 \mathrm{sec}$ & $\downarrow$ & $\downarrow$ & $=$ & $=$ & $=$ & Jarrard \& Becker, 1977 \\
\hline \multicolumn{7}{|c|}{ Maze, Eight-Arm Radial (Eight Out of the Eight Arms Baited) } \\
\hline Retention & $\downarrow$ & $\downarrow$ & $=$ & $=$ & $=$ & Jarrard, 1978a \\
\hline Acquisition & $\downarrow$ & $\downarrow$ & $\downarrow$ & $\downarrow$ & $=$ & Jarrard, 1978a \\
\hline \multicolumn{7}{|c|}{ Maze, Eight-Arm Radial (Four Out of the Eight Arms Baited) } \\
\hline Retention & $\downarrow$ & $\downarrow$ & $=$ & $=$ & $=$ & Jarrard, 1978b \\
\hline
\end{tabular}

Note-All comparisons are with the unoperated control group. Symbols: $\uparrow=$ facilitation, $\downarrow=$ impairment, $==$ equal performance.

described as increased arousal (Campbell, Ballentine, \& Lynch, 1971; Jarrard, 1968, 1973, 1976). Since any differences in reactivity to novelty and increased arousal would be confounded in most activity-testing procedures, we recorded activity in the least novel of all situations, the home cage (Jarrard, 1976). A system was developed that continuously monitors activity, eating, and drinking. As one can see in Table 1, fimbrial and complete hippocampal animals are more active than controls during both the day and night; however, the increases in activity at night are especially large. Using procedures similar to those employed early by Campbell and Sheffield (1953) to study drive, we found that both fimbrial and complete hippocampals are more affected by increased deprivation, while CAl and alveus damage has minimal effects on activity in the home cage. In an unpublished study, Steward and Jarrard (Note 2) have tested rats with extensive entorhinal lesions in our system and found that homecage activity was not different from that of controls during either ad-lib or deprivation conditions. Thus, the hippocampal formation seems to be especially involved in the effects on arousal together with subcortical structures that are "further downstream." Although space does not permit a detailed consideration of this line of research, we have reason to believe that the important area for the increased arousal is the ventral subiculum and the axons that pass through lateral fimbria to points of termination in hypothalamic areas closely linked to endocrine functioning (Meibach \& Siegel, 1977). It is known from results obtained with the Fink-Heimer stain that these axons are damaged in both our fimbria and $\mathrm{CH}$ preparations (Jarrard, 1976). To test the hypothesis that the important area is ventral subiculum, and to avoid the problem of damaging fibers of passage, we are currently doing an experiment using kainic acid to selectively lesion ventral subiculum, dorsal subiculum, and the $\mathrm{CA} 3$ cell field.

\section{Selective Lesions and Interference}

Research with the complex spatial maze was undertaken in order to find out more about the impaired spatial reversal learning obtained in CA1- and alveallesioned animals. In the first study, an eight-arm radial maze similar to the one used by Olton and Samuelson (1976) was employed to look at performance when the task was learned before, as compared with after, the operations (Jarrard, 1978a). Training and testing animals in the eight-arm task involves baiting each of the arms and allowing the animal to choose among the arms until all eight food pellets are found or 16 arms are chosen. The most descriptive analysis of the data is that of the choice-by-choice accuracy carried out for the last 12 days of testing (see Figure 2). The probability of a correct response was used in 


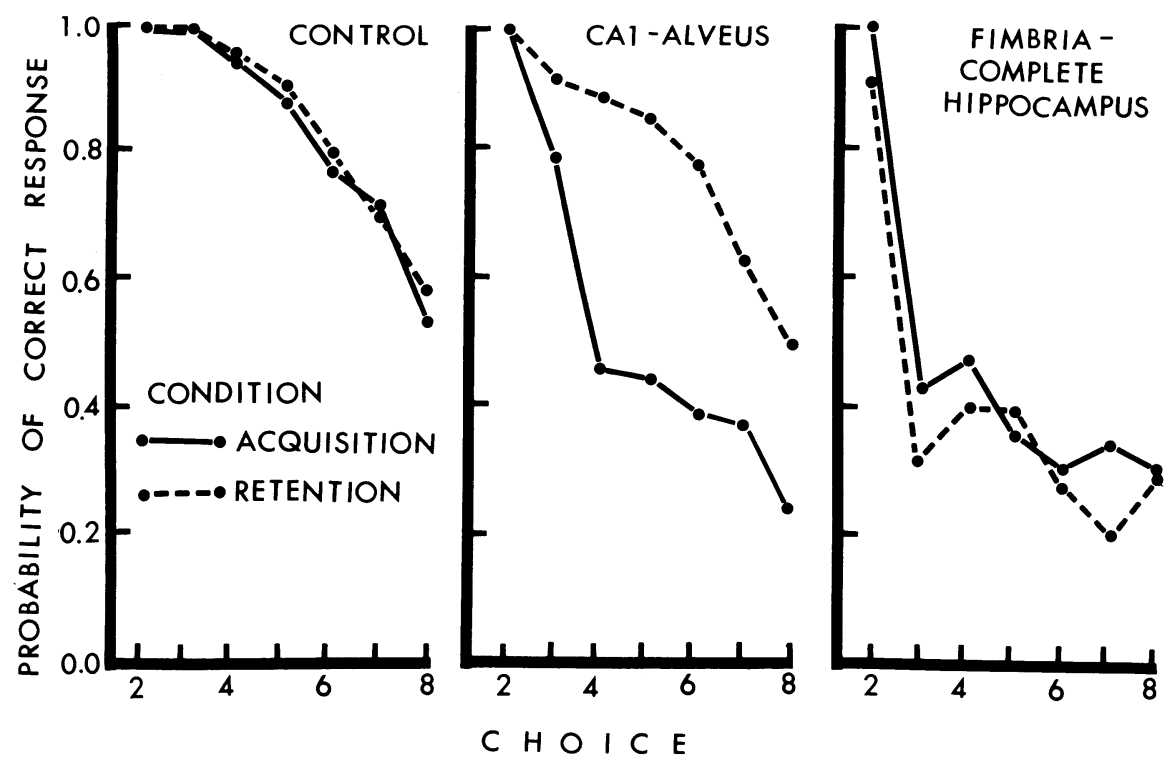

Figure 2. Probability of correct response of Choices 2-8 for groups in the acquisition and retention conditions.

the analysis, in which a score of 1.0 indicates correct responses on every opportunity and a score of 0.0 indicates chance performance. Scores for the operated and unoperated control groups, the CA1 and alveus, and the fimbrial and complete hippocampal groups were each combined, since performance was similar. There were two major results (see Figure 2 and Table 1): (1) rats with CA1 and posterior alveal lesions were impaired in acquisition of the spatial maze when it was learned after the operations, but postoperative performance (retention) was normal when the task was learned before the operations and (2) extensive damage to the hippocampus and lesions limited to the fimbria impaired performance after both preoperative and postoperative training.

An important question to ask is whether or not the nature of the impairment in the different lesion groups is similar. The CA1 cell field and posterior alveus are apparently not necessary for correct performance of the eight-arm maze, since performance was normal when the task was learned before the operations. Thus, spatial information can be utilized following damage to these areas. A general learning impairment is not found in CA1 and alveal animals, since performance is similar to controls in acquisition of other tasks (e.g., passive avoidance, two-way avoidance, DRL); however, the animals do have trouble learning a complex spatial maze. These findings suggest that the CA1 cells and fibers in posterior alveus may be important in acquisition of complex spatial tasks but not necessary once the task is learned. One is reminded of the findings of Adey, Dunlap, and Hendrix (1960) that, early in acquisition of a discrimination task, hippocampal activity preceded that in the entorhinal cortex, whereas, after learning had progressed, the sequence of activity was reversed.

In contrast to these differential effects on acquisition and retention of the spatial task, fimbrial and extensive hippocampal damage impaired performance regardless of when the task was learned. Our previous research with selective lesions indicates that interrupting the axons in fimbria results in several general changes in behavior-an increase in arousal (tonic readiness to respond) and what some writers refer to as a loss of response control or a response-inhibition deficit (Douglas, 1967; Grossman, 1978; Kimble, 1968). Thus, the deficit observed in the spatial maze in $\mathrm{F}$ and $\mathrm{CH}$ animals may be a result of a more general impairment.

In an attempt to obtain a better understanding of the nature of the impairment found in the various groups, a different procedure using the eight-arm maze was devised (Jarrard, 1978b). This involved training the animals to choose only four out of eight arms. In this task, correct performance requires that the subjects learn not only a spatial discrimination (e.g., which four of the eight arms are consistently baited), but also which baited arms have already been visited within a trial. Using the terminology of Honig (1978), the spatial discrimination aspects of the task involve general information that is applicable across many trials and is referred to as reference memory, while remembering which arms have been visited within a trial involves information that is useful for a relatively short time and is referred to as working memory. If the impairment in fimbrial and complete hippocampals is a result of changes of a general nature (arousal or response control, or if the animals are 

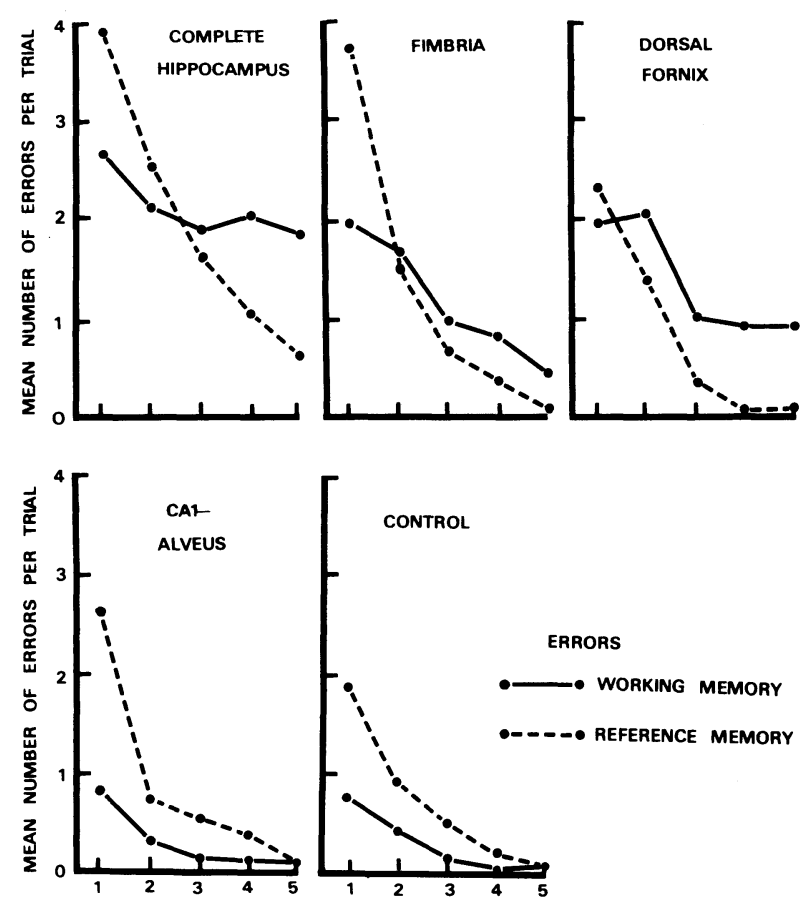

SUCCESSIVE FIFTHS OF TRIALS TO CRITERION

Figure 3. Mean number of working and reference memory errors for groups during successive fifths of trials to criterion.

lost in space), then one would expect these lesioned animals to be impaired on both reference and working memory aspects of the task.

In the experiment, rats were trained before the operations, selective lesions were made, and performance was then tested. Preoperative training consisted of learning to approach the first set of four arms (Problem A) to a criterion (four out of five errorless trials on 3 successive days) and then reversal learning in which the previously incorrect arms were baited (Problem B). After recovery from the operations, the animals were retrained to approach the last four arms that had been learned (Problem B) to either the criterion or a maximum of 205 trials. Reversal learning to Problem A was then carried out. In addition to rats with the usual selective hippocampal lesions, a group of animals with relatively large dorsal fornix lesions was included. Subsequent histological analysis indicated that the dorsal fornix lesions also resulted in damage to the more medial aspects of the fimbria.

Animals with fimbrial, dorsal fornix, and extensive hippocampal lesions required more trials to reach the criterion on both Problems B and A. Performance of animals with CA1 and alveal damage was similar to that of controls. Figure 3 shows the error data (working and reference memory errors) for the immediate postoperative testing on Problem B. Inspection of the error curves for complete hippocampals shows that in the early trials a considerable number of both reference and working memory errors were made. With con- tinued testing, reference memory errors decreased to a level similar to that of controls, while working memory errors persisted (e.g., complete hippocampals continued to reenter baited arms already chosen within a trial, even after more than 200 trials). The pattern of errors for fimbrial and dorsal fornix animals is generally similar to that for complete hippocampals, while errors for CA1-alveal animals and controls are similar. Analysis of errors made during reversal to Problem A presented a similar picture (e.g., $\mathrm{CH}$, fimbrial, and, to a lesser extent, dorsal fornix animals experience difficulty with the working and reference memory components of the task).

Although the problem with working memory is especially prevalent in $\mathrm{CH}$, fimbrial, and dorsal fornix animals, the animals also have difficulty with the reference memory aspects of the task (i.e., they do enter more incorrect, nonbaited arms than controls early in training). This difficulty is especially apparent during reversal training when the previously correct and incorrect arms are reversed. Figure 4 shows the reference memory errors made during the first 25 trials of testing on Problems B and A. It is apparent that rats with $\mathrm{CH}$, fimbrial, and dorsal fornix lesions persist in choosing the previously correct arms when the correct and incorrect arms are reversed. While the impaired subjects did require more trials to relearn Problem B, and thus received more training on the problem before reversal, an analysis of covariance of the data indicated that the differences in amount of experience did not account for the differences made in reference memory errors. These results agree with the often reported finding that animals with hippocampal lesions are more influenced than controls

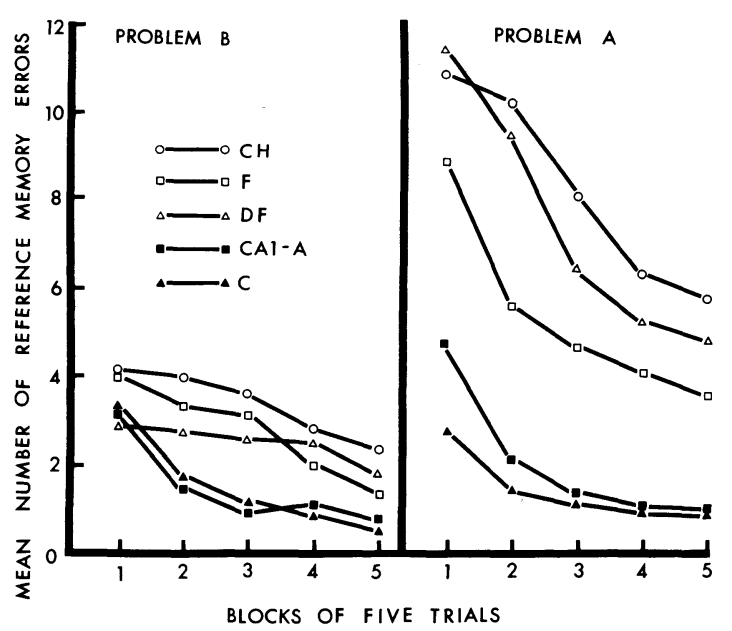

Figure 4. Mean number of reference memory errors for groups during the first 25 trials on Problems B and A. (Abbreviations: $\mathbf{C H}=$ complete hippocampus; $F=$ fimbria; $D F=$ dorsal fornix; CA1-A = CA1 cell field-alveus; $C=$ operated and unoperated control.) 
by previous experience (Douglas, 1967; Jarrard, 1976; Kimble, 1968).

The finding that rats with CA1 and alveal damage were not impaired when learning occurred before the operations is consistent with the results obtained when all eight arms were baited. These animals should be impaired when required to learn the four-out-of-eight task after the operations and subjects are currently being tested in this experiment. The relative performance on the working and reference memory components of the task will be especially interesting.

The results of the above experiment show that rats with selective damage to the rostral hippocampal connections and extensive damage to hippocampus can learn the complex spatial discrimination aspects of the task. Thus, they are not lost in space and they can learn to inhibit responses to consistently unbaited arms. Although these animals experience difficulty when the previously correct and incorrect arms are reversed, the most persistent problem appears to be in remembering which of the baited arms have already been chosen within a trial (i.e., in working memory). A similar difficulty with working memory has been described in fimbria-fornix-lesioned rats by Olton and Papas (1979) when eight arms are consistently baited on a 17-arm maze. While the distinction between reference memory and working memory is useful in analyzing different components of the task, a reasonable question to ask is whether the different errors reflect different underlying processes or whether a similar process is, in fact, involved. Since $\mathrm{CH}$, fimbria, and dorsal fornix animals were impaired in the present experiment on both reference and working memory components of the task, it seems most parsimonious to conclude that a similar process must be involved. Specifically, it is suggested here that the impairment reflects an increased susceptibility to interference when the connections between the hippocampus and subcortical structures are interrupted.

Although a description of the characteristics of working memory is a matter of theoretical debate, most investigators agree than an important variable is the amount of interference (Honig, 1978). In comparing the working and reference memory components of the four-out-of-eight task, a greater amount of interference would be found in remembering which baited arms have already been visited within a trial. The decrease in performance with increasing choices in the eight-out-of-eight task has been attributed to interference produced by previous choices (Olton, 1978). In a previous study, published in 1975, we found that rats with extensive damage to hippocampus are especially susceptible to interference (Jarrard, 1975). In this experiment, subjects were trained before the operations to alternate in the Y-maze, were retrained postoperatively, and then tested with delays between trials. Rats with hippocampal damage were able to relearn the single alter- nation with savings, and to perform as well as controls with delays up to 4 min between trials. However, when an interpolated, interfering activity (forced running in a wheel) was introduced during delays, performance of hippocampals was significantly impaired. Thus, the passage of time did not differentially affect performance, but hippocampals were more susceptible than controls to the interpolated, interfering activity. In agreement with these results, Winocur has carried out a series of experiments demonstrating increased interference in hippocampal rats on visual tasks (Winocur, 1979; Winocur \& Olds, 1978).

Support for an interference interpretation of hippocampal function is also found at the human level in the learning and memory deficits of amnesiacs with known or suspected hippocampal damage. Larry Weiskrantz and his colleagues (Warrington \& Weiskrantz, 1973; Weiskrantz \& Warrington, 1975; Winocur \& Weiskrantz, 1976) have been able to convincingly demonstrate that by systematically manipulating interference, memory in amnesiacs can be controlled.

Interference theory occupies a central role in human learning and memory research and is especially important in theorizing about forgetting (see reviews by Crowder, 1976, and Baddeley, 1976). While it is not possible at the present time to answer the question of why interference is such a problem when there is hippocampal damage, the theories proposed by Hirsh (1974) and more recently by Wickelgren (1979) suggest that the hippocampus is part of a system mediating contextual retrieval and that interfering events cause features of the material that is to be remembered to lose its distinctiveness. Whatever the explanation for the increased susceptibility to interference, our results with selective lesions indicate that the rostral hippocampal connections with subcortical structures are especially involved.

\section{Conclusions}

Even though it has not proved feasible to selectively deefferent the extrahippocampal projections from CA3 and CA1 cell fields by interrupting axons in fimbria and alveus, some interesting differences in behavior are found following damage to these fiber tracts. Because our lesions no doubt damage fibers of passage, any conclusion concerning the involvement of discrete subdivisions must be qualified. With the recent discovery and use of kainic acid as a substance for producing neuronal lesions, it is now possible to obtain more selective cell loss within the hippocampal formation without damaging afferents and fibers of passage. Cells in the hippocampal formation have been shown to be differentially sensitive to the neurotoxin, with the CA3 pyramidal cells being most affected, followed by CA4 cells, subicular pyramids, CA1 cells, and cells in dentate gyrus, in 
that order (Nadler, Perry, \& Cotman, 1978). By using intrahippocampal injections, we have been able to selectively damage cells in the CA3 field, dorsal subiculum, and ventral subiculum-three areas that have different neuroanatomical projections. The more discrete lesions should be useful in behavioral studies.

In conclusion, our research with selective hippocampal lesions involving either the fimbria, CA1 cells, and/or posterior alveus has indicated differential effects on behavior. Specifically, damage to the fimbria with the resulting disruption of rostral subcortical connections is similar to extensive hippocampal lesions in causing increases in behavioral arousal and increased susceptibility to interference; lesions of posterior alveus and damage to CA1 cells have relatively little effect on behavior but do result in impaired acquisition of complex spatial tasks. Since damage to fimbria and alveus interrupts fibers of passage, thus complicating interpretation of the results, the use of chemical lesioning techniques with more discrete damage to hippocampal subdivisions should prove of value in future research.

\section{REFERENCE NOTES}

1. Swanson, L. W. Personal communication, 1977

2. Steward, O., \& Jarrard, L. E. Activity, feeding, and drinking following entorhinal cortical lesions in rats. Unpublished manuscript, 1978. (Available on request from L. E. Jarrard.)

\section{REFERENCES}

Adey, W. R., Dunlap, C. W., \& Hendrix, C. E. Hippocampal slow waves, distribution and phase relationships in the course of approach learning. Archives of Neurology, 1960, 3, 74-90.

Andersen, P., Bland, B. H., \& Dudar, J. D. Organization of the hippocampal output. Experimental Brain Research, 1973, $17,152-168$

Andersen, P., Bliss, T. V. P., \& Skrede, K. K. Lamellar organization of hippocampal excitatory pathways. Experimental Brain Research, 1971, 13, 222-238.

Baddeley, A. D. The psychology of memory. New York: Basic Books, 1976.

Campbell, B. A., Ballentine, P., \& Lynch, G. Hippocampal control of behavioral arousal: Duration of lesion effects and possible interactions with recovery after frontal cortical damage. Experimental Neurology, 1971, 33, 159-170.

Campbell, B. A., \& Sheffield, F. D. Relation of random activity to food deprivation. Journal of Comparative and Physiological Psychology, 1953, 46, 320-322.

Crowder, R. G. Principles of learning and memory. Hillsdale, N.J: Erlbaum, 1976.

Douglas, R. J. The hippocampus and behavior. Psychological Bulletin, 1967, 67, 416-442.

Gottlieb, D. I., \& Cowan, W. M. Autoradiographic studies of the commissural and ipsilateral association connection of the hippocampus and dentate gyrus of the rat. I. The commissural connections. Journal of Comparative Neurology, 1973, 149, 393-422.

Gray, J. A., Jarrard, L. E., Rawlins, J. N. P., \& Feldon, J. The effects of fimbrial and lateral septal lesions upon the partial reinforcement extinction effect in the alley. Experimental Brain Research, 1977, 28, 19-20.
Grossman, S. P. An experimental dissection of the septal syndrome. In Functions of the septohippocampal system. Ciba Foundation Symposium. New York: Elsevier, 1978.

Hirsh, R. The hippocampus and contextual retrieval of information from memory: A theory. Behavioral Biology, 1974, 12, 421-444.

Huorth-Simonsen, A. Hippocampal efferents to the ipsilateral entorhinal area: An experimental study in the rat. Journal of Comparative Neurology, 1971, 142, 417-437.

Huorth-Simonsen, A. Some intrinsic connections of the hippocampus in the rat: An experimental analysis. Journal of Comparative Neurology, 1973, 147, 145-162.

HoNIG, W. K. Studies of working memory in the pigeon. In S. H. Hulse, H. F. Fowler, \& W. K. Honig (Eds.), Cognitive processes in animal behavior. Hillsdale, N.J: Erlbaum, 1978.

JARRARD, L. E. Behavior of hippocampal lesioned rats in home cage and novel situations. Physiology \& Behavior, 1968, 3, 65-70.

Jarrard, L. E. The hippocampus and motivation. Psychological Bulletin, 1973, 79, 1-12.

JARRARD, L. E. The role of interference in retention by rats with hippocampal lesions. Journal of Comparative and Physiological Psychology, 1975, 89, 400-408.

JARRARD, L. E. Anatomical and behavioral analysis of hippocampal cell fields. Journal of Comparative and Physiological Psychology, 1976, 90, 1035-1050.

JARRARD, L. E. Selective hippocampal lesions: Differential effects on performance by rats of a spatial task with preoperative versus postoperative training. Journal of Comparative and Physiological Psychology, 1978, 92, 1119-1127. (a)

JARRARD, L. E. Selective hippocampal lesions and spatial discrimination in the rat. Society for Neuroscience Abstracts, 1978, 3, 222. (b)

JaRrard, L. E., \& Becker, J. T. The effects of selective hippocampal lesions on DRL behavior in rats. Behavioral Biology, 1977, 21, 393-404.

Kimble, D. P. Hippocampus and internal inhibition. Psychological Bulletin, 1968, 70, 285-295.

Koda, L. Y., \& Bцоом, F. E. A light and electron microscopic study of noradrenergic terminals in the rat dentate gyrus. Brain Research, 1977, 120, 327-335.

LORENTE DE No, R. Studies on the structure of the cerebral cortex: 1. The area entorhinalis. Journal of Psychology and Neurology, 1933, 45, 381-438.

LoRENTE DE No, R. Studies on the structure of the cerebral cortex: II. Continuation of the study of the ammonic system. Journal of Psychology and Neurology, 1934, 46, 113-177.

Meibach, R. C., \& Siegel, A. Efferent connections of the hippocampal formation in the rat. Brain Research, 1977, 124, 197-224.

Mellgren, S. I., \& Srebro, B. Changes in acetylcholinesterase and distribution of degenerating fibers in the hippocampal region after septal lesions in the rat. Brain Research, 1973, 52, 19-36.

Moore, R. Y. Monoamine neurons innervating the hippocampal formation and septum: Organization and response to injury. In R. L. Isaacson \& K. H. Pribram (Eds.), The hippocampus (Vol. 1) Structure and development. New York: Plenum Press, 1975.

Moore, R. Y., \& Halaris, A. Hippocampal innervation by serotonin neurons of the midbrain raphe in the rat. Journal of Comparative Neurology, 1976, 164, 171-184.

Mosko, S., Lynch, G., \& Cotman, C. W. The distribution of septal projections to the hippocampus of the rat. Journal of Comparative Neurology, 1973, 152, 163-174.

Nadler, J. V., Perry, B. W., \& Cotman, C. W. Preferential vulnerability of hippocampus to intraventricular kainic acid. In E. G. McGeer, J. W. Olney, \& P. L. McGeer (Eds.), Kainic acid as a tool in neurobiology. New York: Raven Press, 1978. 
Olton, D. S. Characteristics of spatial memory. In S. H. Hulse, H. Fowler, \& W. K. Honig (Eds.), Cognitive aspects of animal behavior. Hillsdale, N.J: Erlbaum, 1978.

Olton, D. S., \& PAPAS, B. C. Spatial memory and hippocampal function. Neuropsychologia, 1979, 17, 669-682.

Olton, D. S., \& Samuelson, R. J. Remembrance of places passed: Spatial memory in rats. Journal of Experimental Psychology: Animal Behavior Processes, 1976, 2, 97-116.

Raisman, G., Cowan, W. M., \& Powell, R. P. S. An experimental analysis of the efferent projection of the hippocampus. Brain, 1966, 89, 83-108.

Rawlins, J. N. P., \& Green, K. F. Lamellar organization in the rat hippocampus. Experimental Brain Research, 1977, 28, 335-344.

Rosen, D. L., \& Van Hoesen, G. W. Hippocampal efferents reach widespread areas of cerebral cortex and amygdala in the rhesus monkey. Science, 1977, 198, 315-317.

Ruth, R. E., \& Routtenberg, A. Extensive granule cell deterioration following anodal electrolytic lesions of dentate gyrus reflects lamellar organization of rat hippocampal formation. Brain Research, 1978, 153, 627-636.

Segal, M. Physiological and pharmacological evidence for a serotonergic projection to the hippocampus. Brain Research, 1975,94, 115-131.

STEWARD, O. Topographic organization of the projections from the entorhinal area to the hippocampal formation of the rat. Journal of Comparative Neurology, 1976, 167, 285-314.

Swanson, L. W. The hippocampus-New anatomical insights. Trends in Neurosciences, 1979, 2, 9-12.

Swanson, L. W., \& Cowan, W. M. An autoradiographic study of the organization of the efferent connections of the hippocampal formation in the rat. Journal of Comparative Neurology, 1977, 172, 49-84.

Swanson, L. W., \& Hartman, B. K. The central adrenergic system. An immunofluorescence study of the location of cell bodies and their efferent connections in the rat utilizing dopamine-B-hydroxylase as a marker. Journal of Comparative Neurology, 1975, 163, 487-506.
Swanson, L. W., Wyss, J. M., \& Cowan, W. M. An autoradiographic study of the organization of intrahippocampal association pathways in the rat. Journal of Comparative Neurology, 1978, 181, 681-715.

Warrington, E. K., \& Weiskrantz, L. An analysis of shortterm and long-term memory deficits in man. In J. A. Deutsch (Ed.), The physiological basis of memory. New York: Academic Press, 1973.

Weiskrantz, L., \& Warrington, E. K. The problem of the amnesic syndrome in man and animals. In R. L. Isaacson \& K. H. Pribram (Eds.), The hippocampus (Vol. 2). New York: Plenum Press, 1975.

Wickelgren, W. A. Chunking and consolidation: A theoretical synthesis of semantic networks, configuring in conditioning, $S-R$ versus cognitive learning, normal forgetting, the amnesic syndrome, and the hippocampal arousal system. Psychological Review, 1979, 86, 44-60.

Winocur, G. The effects of interference on discrimination learning and recall by rats with hippocampal lesions. Physiology \& Behavior, 1979, 22, 339-345.

Winocur, G., \& OLDs, J. Effects of context manipulation on memory and reversal learning in rats with hippocampal lesions. Journal of Comparative and Physiological Psychology, 1978, 92, 312-321.

Winocur, G., \& Weiskrantz, L. An investigation of pairedassociate learning in amnesic patients. Neuropsychologia, 1976, 14, 97-110.

\section{NOTE}

1. Since pyramidal cell field CA2 is small in the rat and CA3 appears to be a central component of the hippocampal neuronal circuit, the terms CA1 and CA3 (which includes CA2 and CA4) will be used here. These terms correspond to the regio superior and regio inferior of Cajal (1911). 